\title{
Diagnosis of oesophageal cancer by detection of minichromosome maintenance 5 protein in gastric aspirates
}

\author{
GH Williams',7, R Swinn ${ }^{2,7}$, AT Prevost ${ }^{3}$, P de Clive-Lowe ${ }^{4}$, I Halsall ${ }^{2}$, JJ Going ${ }^{5}$, CN Hales ${ }^{2}$, K Stoeber, ${ }^{*}$ and \\ SJ Middleton 6
}

'Wolfson Institute for Biomedical Research and Department of Histopathology, University College London, The Cruciform Building, Gower Street, London WCIE 6BT, UK; ${ }^{2}$ Department of Clinical Biochemistry, University of Cambridge, Level 4, Laboratory Block, Box 232, Addenbrooke's Hospital, Hills Road, Cambridge CB2 2QR, UK; ${ }^{3}$ Department of Public Health and Primary Care, Centre for Applied Medical Statistics, University of Cambridge, University Fonvie Site, Robinson Way, Cambridge CB2 2SR, UK: ${ }^{4}$ Department of Urology, Box 43, Addenbrooke's Hospital National Health Service Trust, Hills Road, Cambridge CB2 2QQ, UK; ${ }^{5}$ Department of Pathology, Glasgow University, Glasgow Royal Infirmary, Castle Street, Glasgow G4 OSF, UK; ${ }^{6}$ Department of Gastroenterology, Addenbrooke's Hospital National Health Senvice Trust, Hills Road, Cambridge CB2 2QQ, UK

Symptomatic oesophageal cancer is usually advanced and the prognosis poor. Lethality of symptomatic oesophageal cancer has motivated screening for these diseases earlier in their evolution, but reliable methods for early diagnosis remain elusive. We have demonstrated that dysregulated expression of minichromosome maintenance (MCM) proteins 2-7 is characteristic of early epithelial carcinogenesis, and that these key DNA replication initiation factors can be used as diagnostic markers for cervical and genito-urinary tract cancer. In this study, we investigated whether minichromosome maintenance protein 5 (Mcm5) can be used to detect oesophageal cancer cells in gastric aspirates. Two monoclonal antibodies raised against His-tagged human Mcm5 were used in a timeresolved immunofluorometric assay to measure $\mathrm{Mcm} 5$ levels in cells isolated from gastric aspirates of 40 patients undergoing gastroscopy for suspected or known oesophageal carcinoma or symptoms of dyspepsia. The test discriminated with high specificity and sensitivity between patients with and without oesophageal cancer (85\% sensitivity (95\% confidence interval $(\mathrm{Cl})=62-97 \%)$, $85 \%$ specificity $(\mathrm{Cl}=66-96 \%)$ ), as demonstrated by the large area under the receiver operating characteristics curve $(0.93$ ( $95 \%$ $\mathrm{Cl}=0.85-0.99)$ ). Elevated levels of $\mathrm{Mcm} 5$ in gastric aspirates are highly predictive of oesophageal cancer. This simple test for oesophageal cancer is readily automated with potential applications in primary diagnosis, surveillance and screening.

British Journal of Cancer (2004) 91, 7|4-719. doi: 10.1038/sj.bjc.6602028 www.bjcancer.com

Published online 20 July 2004

(c) 2004 Cancer Research UK

Keywords: Mcm5; DNA replication licensing; diagnosis; oesophageal cancer

The incidence of oesophageal cancer in Western societies is increasing rapidly (Blot et al, 1991) and currently stands at approximately 6 per 100000 in England and Wales (Office for National Statistics England and Wales, 1999). It accounts for about 6700 cancer-related deaths per year in the UK (Cancer Research Campaign, 1998, 1999). Most patients are not candidates for curative treatment as the symptoms associated with oesophageal cancer predominantly arise when the tumour is at an advanced stage. Without curative treatment, the overall mean survival of patients with oesophageal cancer is 6 months, even including those patients deemed suitable for curative treatment, the overall survival is poor, about $5 \%$ at 5 years (Newnham et al, 2003).

However, when applied to patients with very early disease, the latest chemotherapy regimes offer excellent results, and 5-year survival for T1-2N0 disease is now greater than $80 \%$ (Urschel and Vasan, 2003). Therefore, at present, the key to successful treatment

*Correspondence: Dr K Stoeber; E-mail: k.stoeber@ucl.ac.uk

7 Both these authors contributed equally to this work

Received 7 January 2004; revised 12 May 2004; accepted 18 May 2004; published online 20 July 2004 of oesophageal cancer is early diagnosis and there is consequently great interest in the development of a screening test that will identify patients with asymptomatic oesophageal malignant or premalignant disease. Patients with Barrett's oesophagus (Miros et al, 1991), known to have a high risk of developing oesophageal carcinoma, can be screened endoscopically, but this is time consuming and of questionable effectiveness. An extension of current endoscopic screening to include patients with gastrooesophageal reflux disease would have even less cost effectiveness, even though this group is at increased risk of developing oesophageal cancer (Iftikhar et al, 1992). Certain risk factors such as cigarette smoking (Brown et al, 1994; Hu et al, 1994; Rolon et al, 1995), alcohol (Brown et al, 1994; Hu et al, 1994; Rolon et al, 1995) and age (Office for National Statistics England and Wales, 1999) are also associated with higher risk but again lack suitable specificity to be useful as screening tools.

Population screening for squamous oesophageal carcinoma is only practised where the incidence is high such as Japan and China using techniques such as abrasive cytology, barium oesophagography and fibreoptic oesophagoscopy (Riddell, 1996). This is a labour-intensive approach requiring skilled cytopathologists, gastroenterologists and radiologists. Dysplasia and cancer 
surveillance by endoscopy and biopsy of Barrett's patients in Western populations is also undertaken, but with uncertain benefit (Macdonald et al, 2000).

Despite advances in the molecular pathology of oesophageal neoplasia, no useful clinical biomarkers have yet been identified for diagnostic and screening applications. The initiation of DNA replication represents a final and critical step in growth regulation and lies downstream at the convergence point of growth regulatory pathways (Williams and Stoeber, 1999). Proteins of the minichromosome maintenance (MCM) family (minichromosome maintenance protein $2-7, \mathrm{Mcm} 2-7$ ) play a critical role (DNA replicative helicase) in the initiation of DNA replication (Bell and Dutta, 2002). We have previously demonstrated that dysregulation of MCM proteins is an early event in epithelial carcinogenesis, resulting in exfoliation of MCM-positive tumour cells, and have used these novel biomarkers of growth in diagnostic screening applications for cervical and genitourinary tract cancer (Williams et al, 1998; Stoeber et al, 1999; Stoeber et al, 2002). Moreover, we have shown that dysregulation of the DNA replication initiation pathway is an early event in oesophageal carcinogenesis with aberrant expression of MCM proteins occurring in both squamous dysplasia and glandular dysplasia complicating Barrett's oesophagus (Going et al, 2002).

These data suggest that detection of MCM proteins in exfoliated tumour cells might provide a potentially sensitive indicator of oesophageal neoplasia. Here, we describe an evaluation of this approach using a liquid phase immunofluorometric assay to measure quantitatively $\mathrm{Mcm} 5$ levels in gastric luminal samples obtained from patients undergoing gastroscopy for upper gastrointestinal symptoms. Gastric luminal secretions can be obtained without the need for endoscopy, and can be collected in health centres as a screening tool.

\section{MATERIALS AND METHODS}

\section{Study subjects}

Gastric aspirates were obtained from 40 patients undergoing gastroscopy at Addenbrookes Hospital National Health Service Trust (Cambridge, UK) for suspected or known oesophageal carcinoma or symptoms of dyspepsia. All patients gave full consent and the study was approved by the Local Research Ethics Committee. Aspirates were obtained through the endoscope suction channel. A full endoscopic examination of the oesophagus, stomach and duodenum was performed. Endoscopies were undertaken with conscious sedation using Midazolam. Punch biopsies were taken from regions that looked abnormal to identify any underlying pathological process. Aspirates were analysed in a blinded manner for immunofluorometric $\mathrm{Mcm} 5$ detection. On completion of the study, patient data were decoded and the immunofluorometric signals compared with endoscopy and biopsy histology results.

\section{Gastric aspirates collection and storage}

Prior to biopsy sampling, an endoscope was passed carefully down the oesophagus, which was inflated with air thus minimising any contact with the oesophageal surface. Gastric juice was then aspirated immediately to reduce instrument-related trauma. Gastric aspirates were kept on ice until processing for storage. Storage buffer $(10 \times$ phosphate-buffered saline (PBS), $5 \%$ bovine serum albumin (BSA), $1 \mathrm{~m}$ sucrose, $0.2 \% \mathrm{NaN}_{3}$ ) containing one complete EDTA-free protease inhibitor cocktail tablet (Roche Diagnostics Ltd, Lewes, East Sussex, UK) per $10 \mathrm{ml}$ of buffer was added to gastric aspirates at one-tenth aspirate volume and carefully mixed with the sample. Gastric aspirates in storage buffer were transferred into $5 \mathrm{ml}$ cryovials and stored in liquid nitrogen
$\left(\mathrm{LN}_{2}\right)$ for cryopreservation. The aspirates were stored in $\mathrm{LN}_{2}$ within $5 \mathrm{~h}$ of the samples being collected.

\section{Processing of standards and gastric aspirates}

Standards for the immunofluorometric $\mathrm{Mcm} 5$ assay were prepared, and standards and gastric samples processed as described previously (Stoeber et al, 2002). Briefly, standards and clinical samples were thawed, and the cells were isolated by centrifugation at $1500 \mathrm{~g}$ for $5 \mathrm{~min}$ at $4{ }^{\circ} \mathrm{C}$. The supernatants were discarded, and the cell pellets were washed three times with $500 \mu$ l of PBS. Cell pellets were resuspended in $250 \mu \mathrm{l}$ (for those pellets with a volume less than approximately $200 \mu \mathrm{l}$ ) or $500 \mu \mathrm{l}$ (for those pellets with a volume greater than approximately $200 \mu \mathrm{l}$ ) of processing buffer (PBS, $0.4 \%$ sodium dodecyl sulphate (SDS), $0.02 \% \mathrm{NaN}_{3}$ ). Cell lysates were prepared by incubating the resuspended samples at $95^{\circ} \mathrm{C}$ for $45 \mathrm{~min}$. The DNA in each sample was sheared by passing the lysates through a 21-gauge needle (Becton Dickinson UK Ltd, Cowley, Oxford, UK), and nucleic acids were digested with DNase I $\left(20 \mathrm{U} \mathrm{ml}^{-1}\right.$; Roche Diagnostics) and RNase A $\left(1 \mu \mathrm{g} \mathrm{ml}^{-1}\right.$; Roche Diagnostics) for $2 \mathrm{~h}$ at $37^{\circ} \mathrm{C}$. The samples were centrifuged at $15000 \mathrm{~g}$ for $10 \mathrm{~min}$ to pellet the cell debris, the supernatants were collected and $50 \mu \mathrm{l}$ of each was directly used in the immunofluorometric assay.

\section{Immunofluorometric measurement of Mcm5 levels in gastric aspirates}

Monoclonal antibodies (MAbs) 12A7 and 4B4 raised against Histagged human Mcm5 were protein A purified from hybridoma supernatants as described previously (Stoeber et al, 2002). Protein A-purified MAb 4B4 was labelled with europium using a DELFIA ${ }^{\circledR}$ Eu-labelling kit (Perkin-Elmer Life Science, Wallac Oy, Turku, Finland) according to the manufacturer's instructions. The assay was standardised using HeLa cells as described previously (Stoeber et al, 2002), and one fluorescence unit was defined as the signal generated by the Mcm5 contents of one proliferating HeLa S3 cell, approximately $10^{5} \mathrm{Mcm} 5$ molecules (Kearsey and Labib, 1998). DELFIA ${ }^{\circledR}$ research reagents were obtained from Perkin-Elmer Life Science. All other reagents were obtained from Sigma-Aldrich.

Immunofluorometric measurements of $\mathrm{Mcm} 5$ levels were performed as described previously (Stoeber et al, 2002). Standard curves were constructed from fluorescence values generated by the blank and standard wells, and the fluorescence values of the gastric aspirate samples were calculated with the Multicalc Advanced Immunoassay Data Management package (Perkin-Elmer Life Science). For immunofluorometric measurement of Mcm5 levels, assay standards, control samples and gastric aspirate samples were run as duplicates and the mean of the duplicate results reported. For acceptance of immunofluorometric measurements in the assay, the following coefficients of variations were required: CV $<20 \%$ for results between 1500 and 5000 cells well $^{-1}$ standard curve points; CV $<15 \%$ for results between 5000 and 15000 cells well $^{-1}$; and CV $<10 \%$ for results $>15000$ cells well $^{-1}$.

\section{Immunoassay performance}

In our analysis, we used 1500 cells well $^{-1}$ as the lower detection limit because the within-batch coefficient of variation of the assay was less than $25 \%$ in all samples with cell dilutions above 1500 cells well ${ }^{-1}$, but in only one-quarter of samples below this limit. Samples that generated a fluorescence signal below that corresponding to 1500 cells well $^{-1}$ were reported as having fewer than 1500 cells well $^{-1}$.

\section{Immunohistochemistry}

Formalin-fixed, paraffin-embedded surgical biopsy material from tumour-positive cases was selected for immunohistochemical 
Table I Patient demographics and sample characteristics at endoscopy and biopsy

\begin{tabular}{|c|c|}
\hline Patient characteristics ( $n=40$ patients) & $\begin{array}{c}N(\%) \text { or median } \\
\text { (interquartile range) }\end{array}$ \\
\hline \multicolumn{2}{|l|}{ Sex } \\
\hline Male & $24(60 \%)$ \\
\hline Female & $16(40 \%)$ \\
\hline Age (years) & $74(58-82)$ \\
\hline \multicolumn{2}{|l|}{ Sample characteristics $(n=47 \text { samples })^{\mathrm{a}}$} \\
\hline Gastric aspirate volume $(\mathrm{ml})$ & $4(4-4.5)$ \\
\hline \multicolumn{2}{|l|}{ Endoscopy and/or biopsy findings } \\
\hline Tumour absent & $27(57 \%)$ \\
\hline Normal oesophagus & 2 \\
\hline Diverticulum & 1 \\
\hline Shatski ring & I \\
\hline Chemical gastropathy & i \\
\hline Oesophagitis ${ }^{b}$ & 9 \\
\hline Barrett's oesophagus without dysplasia & 13 \\
\hline Tumour present & $20(43 \%)$ \\
\hline $\mathrm{AdCa}^{c}$ & 10 \\
\hline SCC & 10 \\
\hline \multicolumn{2}{|l|}{ Tumour stage } \\
\hline T2NOMO & I \\
\hline T3NOMO & 9 \\
\hline T3NOMI & i \\
\hline T3NIMO & i \\
\hline T3NIMI & i \\
\hline T4NIMO & i \\
\hline
\end{tabular}

$\mathrm{AdCa}=$ adenocarcinoma; $\mathrm{SCC}=$ squamous cell carcinoma. ${ }^{a}$ Two samples from one patient with $\mathrm{AdCa}$, four samples from one patient and two samples from two patients with SCC, and two samples from one patient with Barrett's oesophagus with

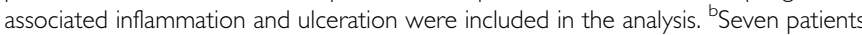
with oesophagitis had ulceration. 'Three AdCa's had associated severely atypical Barrett's oesophagitis.

analysis. Automatic immunostaining for $\mathrm{Mcm} 2$ and $\mathrm{Mcm} 5$ was performed on a DAKO Techmate ${ }^{\mathrm{TM}} 500$ as described previously (Stoeber et al, 2001). Primary antibodies were omitted in negative controls and in addition appropriate tissue sections were used as positive and negative controls. Microscopic images were acquired with an Olympus BX51 light microscope/CCD camera set-up and ANAlysis image capturing software (Soft Imaging Systems $\mathrm{GmbH}$, Münster, Germany). A semi-quantitative determination of the extent of staining was obtained by calculating a labelling index for each protein stained. At least 200 nuclei were assessed per case. Results were expressed as a percentage of positively stained nuclei out of the total number of nuclei counted in representative microscopic fields. The median and range of labelling indices were calculated.

\section{Statistical analysis}

Sensitivity and specificity characteristics of the immunofluorometric Mcm5 test for the detection of oesophageal cancer are presented as a receiver operating characteristics (ROC) curve. The area under the nonparametric ROC curve was used to assess the overall accuracy of the test (McNeil and Hanley, 1984; Altman and Bland, 1994). Three cut points were used to demonstrate test performance under different circumstances as follows: at the lower detection limit of the assay (i.e. 1500 cells well $^{-1}$ ), where sensitivity of the test was maximal; at the point where the false-positive and false-negative rates of the test were equal (i.e. 5000 cells well $^{-1}$ ); and where specificity exceeded $95 \%$ (i.e. 7500 cells well $^{-1}$ ). An exact $95 \%$ confidence interval (CI) for each proportion, including

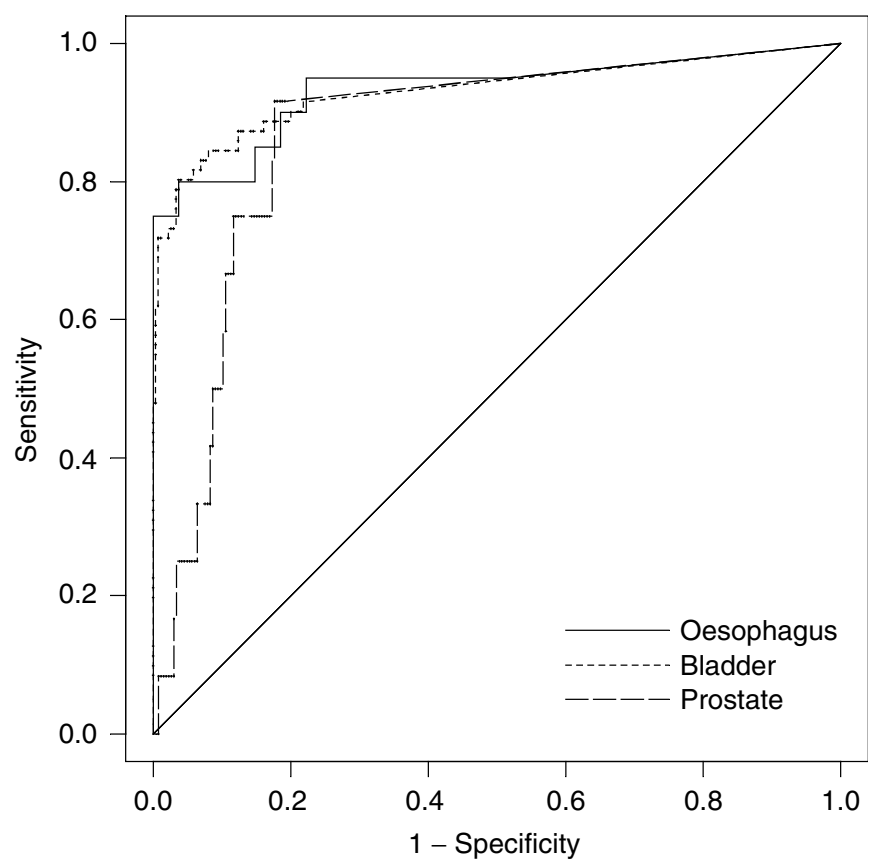

Figure I ROC curve of immunofluorometric Mcm5 test. The jagged curve (solid line) is the nonparametric ROC curve. The diagonal line is a reference line. Area under curve $=0.93(95 \% \mathrm{Cl}=0.85-0.99)$. ROC curves for detection of bladder cancer (jagged dotted line) and prostate cancer (jagged dashed line) are shown for comparison.

Table 2 Sensitivity, specificity and predictive values of the Mcm5 test for oesophageal cancer $^{\mathrm{a}}$

\begin{tabular}{lcccc}
\hline Test & $\begin{array}{c}\text { \% Sensitivity } \\
(\mathbf{9 5 \%} \text { Cl) }\end{array}$ & $\begin{array}{c}\text { Specificity } \\
\mathbf{( 9 5 \%} \mathbf{~ C l )}\end{array}$ & $\begin{array}{c}\text { \% PPV } \\
\mathbf{( 9 5 \% ~ C l ) ~}\end{array}$ & $\begin{array}{c}\text { \% NPV } \\
\mathbf{( 9 5 \% ~ C l ) ~}\end{array}$ \\
\hline $\begin{array}{l}\text { Mcm5 test } \geqslant 1500 \\
\text { cut point }\end{array}$ & $95(75-99)$ & $48(29-68)$ & $58(39-75)$ & $93(66-99)$ \\
$\begin{array}{l}\text { Mcm5 test } \geqslant 5000 \\
\text { cut point }\end{array}$ & $85(62-97)$ & $85(66-96)$ & $81(58-95)$ & $88(70-98)$ \\
$\begin{array}{l}\text { Mcm5 test } \geqslant 7500 \\
\text { cut point }\end{array}$ & $75(51-91)$ & $96(81-99)$ & $94(70-99)$ & $84(66-95)$ \\
\hline
\end{tabular}

$\mathrm{Mcm} 5=$ minichromosome maintenance protein $5 ; \mathrm{Cl}=$ confidence interval

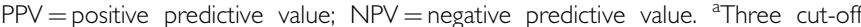
points were used to demonstrate test performance under different circumstances as follows: at the lower detection limit of the assay (fluorescence signal generated from I 500 proliferating HeLa S3 cells well ${ }^{-1}$ ), where sensitivity of the test was maximal; at the point where the false-positive and false-negative rates of the test were equal (5000 cells well ${ }^{-1}$ ); and where specificity exceeded 95\% (7500 cells well ${ }^{-1}$ ).

sensitivity, specificity and predictive values of Mcm5 and cytology, was derived assuming a binomial distribution using StatXact software, Version 4.0 (Cytel Software Corporation, Cambridge, MA, USA). Unless otherwise stated, statistical tests were performed using SPSS software, Version 11.5 (SPSS Inc., Chicago, IL, USA). The level of the signal was compared between patient groups using the Kruskal-Wallis test and for pairs of groups using the MannWhitney $U$-test. All statistical tests were two-tailed, and a $5 \%$ level was used to indicate statistical significance.

\section{RESULTS}

The patient characteristics, clinical symptoms on presentation, endoscopy findings and histopathological diagnoses derived from the 47 gastric aspirate samples were obtained for analysis (Table 1). 
Table 3 Immunofluorometric $\mathrm{Mcm} 5$ test performance in patient groups

\begin{tabular}{lrrlc}
\hline $\begin{array}{l}\text { Patient groups } \\
\text { and subgroups }\end{array}$ & $\begin{array}{c}\text { Group } \\
\text { size }(\mathbf{N})\end{array}$ & $\begin{array}{c}\text { Median } \\
\text { signal }\end{array}$ & $\begin{array}{c}\text { Interquartile } \\
\text { range }\end{array}$ & $\begin{array}{c}\text { Signals } \geqslant \mathbf{5 0 0 0} \\
(\mathbf{9 5 \%} \mathbf{C l})\end{array}$ \\
\hline Negative for cancer & 27 & $17 \mid 8$ & $<1500-2897$ & $15(4-34)$ \\
No ulceration & 20 & $<1500$ & $<1500-<2115$ & $5(1-25)$ \\
Ulceration & 7 & $487 \mid$ & $2897-6732$ & $43(10-82)$ \\
Oesophageal cancer & 20 & $1640 \mid$ & $7263-29822$ & $85(62-97)$ \\
AdCa & 10 & 11210 & $5023-23692$ & $80(44-97)$ \\
SCC & 10 & 25036 & $9752-34221$ & $90(56-99)$ \\
\hline
\end{tabular}

$\mathrm{Mcm} 5=$ minichromosome maintenance protein $5 ; \mathrm{Cl}=$ confidence interval; $\mathrm{AdCa}=$ adenocarcinoma; $\mathrm{SCC}=$ squamous cell carcinoma

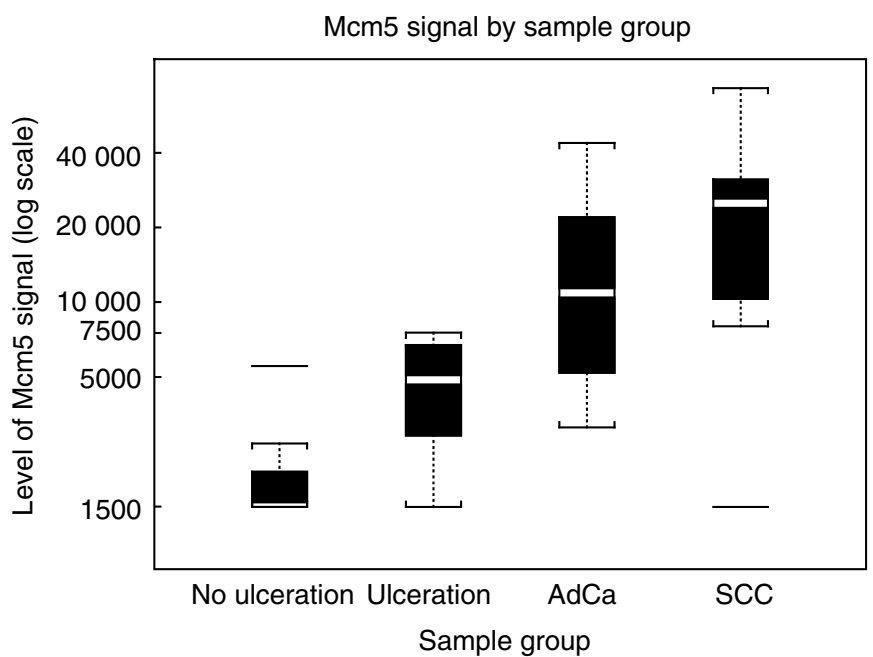

Figure 2 Mcm5 signal by sample group. Each box represents the interquartile range of the Mcm5 signal data for the corresponding sample group. The horizontal line inside the box represents the median signal. Any signal further than 1.5 times the interquartile range is considered as an outlying signal value and plotted separately. The dotted lines extend I.5 times the interquartile range from the limits of the box.

Five of the 40 patients provided more than one sample during follow-up. The patients' median age was 74 years (range 40-90 years) and $60 \%$ were male. The $20(43 \%)$ tumour samples comprised 10 adenocarcinomas (AdCa) and 10 squamous cell carcinomas (SCC). Three of the AdCas were found in association with severely dysplastic Barrett's oesophagus. A total of 13 patients were diagnosed with metaplastic Barrett's oesophagus without associated dysplasia. Seven patients were found to have benign ulceration in a background of inflammatory oesophagitis.

The performance of the immunofluorometric $\mathrm{Mcm} 5$ assay as a diagnostic test for oesophageal cancer is shown as a ROC curve (Figure 1). The test discriminated, with high specificity and sensitivity, between patients with and without oesophageal cancer, as demonstrated by the large area under the ROC curve $(0.93$ (95\% $\mathrm{CI}=0.85-0.99)$ ), which was statistically significantly larger than the area predicted by the null hypothesis $(0.5)(P<0.001)$. In other words, a randomly selected patient with oesophageal cancer would have a 93\% probability of having an immunofluorometric $\mathrm{Mcm} 5$ value that is larger than a randomly selected patient without a malignancy.

Evaluation of the test is demonstrated in Table 2 at different performance levels at cut-point values of 1500 cells well $^{-1}$ (lower detection limit of the assay), 5000 cells well $^{-1}$ (equal false-positive and false-negative rates) and 7500 cells well $^{-1}$ (high specificity). At the 1500 -cell cut point, the test had $95 \%$ (19 of 20) sensitivity and $58 \%$ (19 of 33) positive predictive value. At the 5000-cell cut point,
A

B
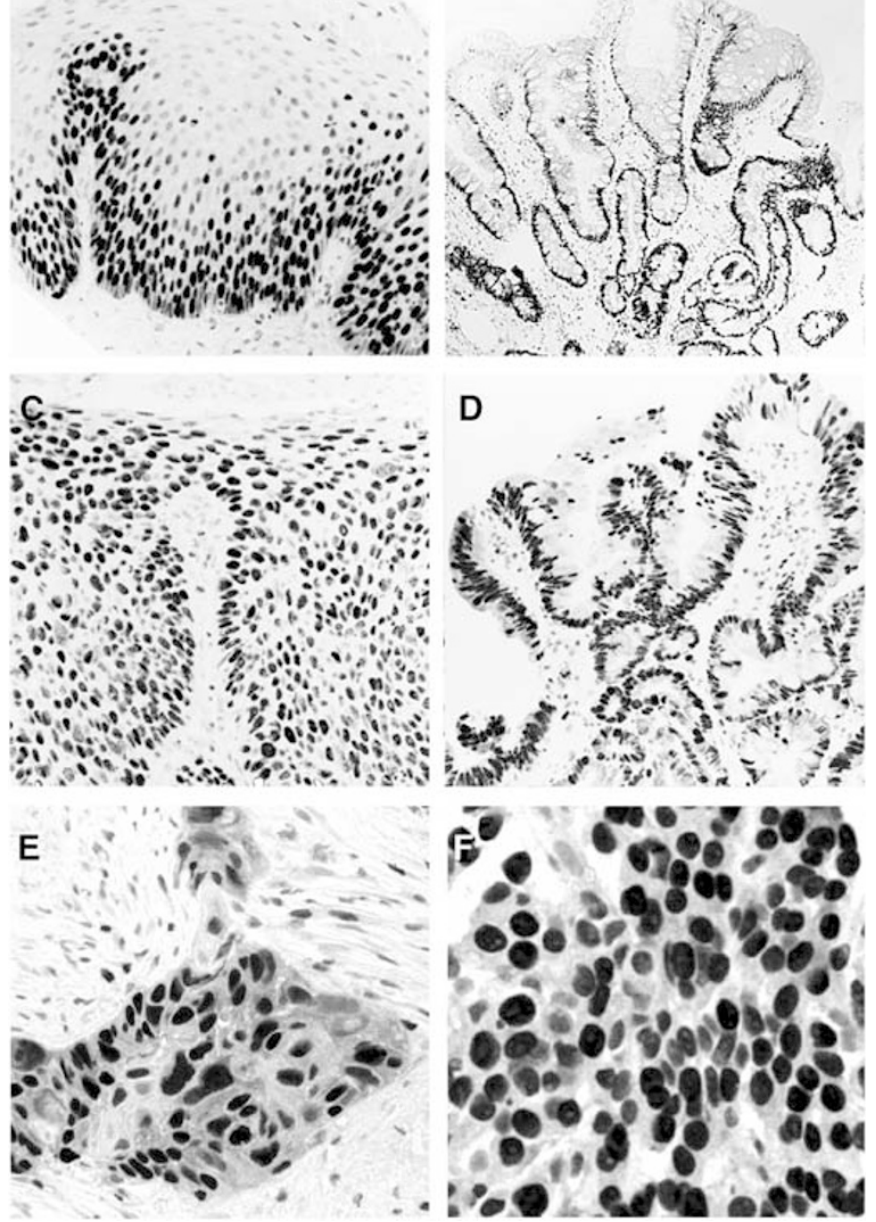

Figure $3 \mathrm{Mcm} 2$ protein expression in normal and neoplastic oesophagus. (A) Normal squamous epithelium showing $\mathrm{Mcm} 2$ expression restricted to the basal proliferative compartment. Onset of the differentiation programme is associated with downregulation of the MCM replication licensing factors. Mcm2 expression is undetectable in surface terminally differentiated cells. (B) Nondysplastic testinal-type 'specialised' Barrett's mucosa showing $\mathrm{Mcm} 2$ expression in cells in the proliferative zone beneath the mucosal surface. Mcm2 expression is markedly downregulated as cells execute their differentiation programme and migrate onto the mucosal surface. (C) Low- to high-grade squamous dysplasia showing high levels of $\mathrm{Mcm} 2$ expression. The arrest in differentiation is associated with persistant Mcm2 expression in surface layers. (D) Low-grade Barrett's dysplasia showing high levels of $\mathrm{Mcm} 2$ expression in upper crypts and surface layers. The failure of dysplastic cells to execute their differentiation programme (maturation arrest) is associated with persistent expression of the MCM replication licensing factors in upper crypt and surface epithelium. (E) Moderately to poorly differentiated SCC showing high levels of $\mathrm{Mcm} 2$ expression. Occasional viable $\mathrm{Mcm} 2$ negative cells are present showing morphological features of differentiation (keratinisation). (F) Poorly differentiated $\mathrm{AdCa}$ showing high levels of $\mathrm{Mcm} 2$ expression. Occasional viable $\mathrm{Mcm} 2$-negative cells are also present showing some features of glandular differentiation (mucin production)

the test had $85 \%$ ( 17 of 20 ) sensitivity and $81 \%$ (17 of 21 ) positive predictive value. At the 7500 -cell cut point, the test had $75 \%$ (15 of 20 ) sensitivity and $94 \%$ ( 15 of 16 ) positive predictive value.

Table 3 and Figure 2 show the performance of the immunofluorometric $\mathrm{Mcm} 5$ test according to the diagnosis made at clinical follow-up using endoscopy findings and histopathological diagnosis as the gold standard. The level of signal in the four 
subgroups was significantly different (Kruskal-Wallis test, $P<0.001)$. Interestingly, the $\mathrm{Mcm} 5$ immunofluorometric signal for patients with ulceration (median 4871) was higher than for other patients without malignancy, where the median signal was below the lower detection limit of 1500 cells well $^{-1}$ (MannWhitney $U$-test, $P=0.002)$. The level of signal was not significantly different (Mann - Whitney $U$-test, $P=0.16$ ) between AdCas (median 11210) and SCCs (median 25036). The largest difference (Mann-Whitney $U$-test, $P<0.001$ ) was between those samples from patients without tumour (median 1718) and those with tumour (median 16 401).

The elevated levels of the Mcm5 DNA replication licensing protein found in gastric aspirates from patients with oesophageal cancer is consistent with our previous immunohistochemical findings demonstrating aberrant expression of $\mathrm{Mcm} 2$ and $\mathrm{Mcm} 5$ proteins in dysplastic and malignant oesophageal lesions (Going et al, 2002). Immunohistochemical analysis of the tumours detected in this study confirms our previous findings showing high levels of MCM protein expression, with the majority of tumour cells expressing the $\mathrm{Mcm} 2$ and $\mathrm{Mcm} 5$ replication licensing factors (SCCs: Mcm2 (92-98\%, mean: 95\%), Mcm5 (93-100\%, mean: 96\%); AdCas: Mcm2 (83-99\%, mean: 94\%), Mcm5 (9098\%, mean: 94\%); Figure 3).

\section{DISCUSSION}

Patients with oesophageal cancer present at an advanced stage, symptoms are usually of recent origin and their period of survival is short. The incidence of oesophageal cancer is increasing and therefore there is an urgent need for reliable cost effective methods for early diagnosis (Wang et al, 1997). Abrasive brush cytology as a screening technique for oesophageal cancer has been used for many years in high incidence areas of China (Shu, 1983). Although the brush biopsy capsule is inexpensive, the hidden costs including preparation of slides and expert cytopathological assessment are considerable. Moreover, despite the alarming increase in the incidence of AdCa of the oesophagus in North America and Europe, screening for neoplasia in Barrett's oesophagus is controversial partly due to the invasive nature and expense of introducing endoscopic biopsy surveillance programmes (Wright et al, 1996).

Maturation arrest and failure to engage correctly the differentiation programme, the hallmark of dysplastic precancerous lesions, is associated with aberrant expression of the MCM replication initiation factors (Williams et al, 1998; Stoeber et al, 1999; Going et al, 2002; Stoeber et al, 2002). Importantly, aberrant expression of MCM proteins was identified in both squamous dysplasia and Barrett's glandular dysplasia, but not in Barrett's metaplastic oesophagus (Figure 3; Going et al, 2002). We have previously shown that detection of MCM proteins in urine sediments is a sensitive and specific test for urothelial neoplasia allowing detection of bladder cancers at all stages and grades including severe dysplasia/carcinoma in situ, the latter corresponding to a similar step in tumour progression represented by dysplastic Barrett's oesophagus (Stoeber et al, 1999, 2002).
Using a similar analytical approach previously applied to the genitourinary tract (Stoeber et al, 2002), application of the immunofluorometric $\mathrm{Mcm} 5$ test to gastric aspirates has resulted in a strikingly similar performance (Tables 2 and 3 and Figure 1). Patients with tumours, including three cases with associated severe dysplastic Barrett's oesophagus, were detected with high sensitivity (85-95\% at the low cut-off point). Importantly, inflammatory conditions including oesophagitis and Barrett's metaplastic oesophagus were not associated with false-positive results. Interestingly, ulcerative lesions gave a signal, but with an amplitude below that generated by tumours, most likely reflecting reparative growth with exposure of the stem-transit compartment to luminal secretions and the shedding of reactive $\mathrm{Mcm} 5$-positive cells. Similar results were found in the urinary tract in relation to renal calculi (Stoeber et al, 2002).

The immunofluorometric Mcm5 test provides a new approach to the detection of oesophageal cancer. Given the magnitude in the difference between $\mathrm{Mcm} 5$ levels in benign and malignant disease found in this study, it is likely that even small cases at an early stage will be detected. Studies on large unselected populations will now be required to determine whether this novel diagnostic approach can be exploited as a screening tool to detect early curable tumours. Furthermore, our previous studies have shown that aberrant expression of the MCM proteins is a powerful marker of dysplasia in Barrett's oesopagus (Going et al, 2002). These data suggest that the immunofluorometric Mcm5 test could be further refined for screening of Barrett's oesophagus by employing balloon cytology catheters, increasing the yield of cellular material for biochemical analysis (Liu et al, 1994; Sepehr et al, 2000). The sensitivity and specificity data are strikingly similar when comparing oesophageal cancer with genitourinary tract cancers. The areas under the ROC curve for oesophagus, bladder and prostate are all around 0.93 (Figure 1; Stoeber et al, 2002). It is likely that similar results will be obtained for other cancers arising from self-renewing tissues using this approach.

These pilot data, including our previous studies examining the expression profile of MCM proteins during oesophageal carcinogenesis, suggest that immunofluorometric detection of $\mathrm{Mcm} 5$ in gastric aspirates provides a new approach for the detection of oesophageal neoplasia. Its use as a screening and diagnostic tool for oesophageal neoplasia needs to be urgently investigated considering the increasing incidence and high mortality rate associated with this disease.

\section{ACKNOWLEDGEMENTS}

This work has been funded by Cancer Research UK, the Department of Clinical Biochemistry, University of Cambridge, Cambridge, UK and the Department of Gastroenterology, Addenbrooke's Hospital National Health Service Trust, Cambridge, UK. We are grateful to Lisa Happerfield and Craig Williams for their technical assistance in the immunohistochemical staining of tissue sections and image capturing/processing.

\section{REFERENCES}

Altman DG, Bland JM (1994) Diagnostic tests 3: receiver operating characteristic plots. BMJ 309: 188

Bell SP, Dutta A (2002) DNA replication in eukaryotic cells. Annu Rev Biochem 71: $333-374$

Blot WJ, Devesa SS, Kneller RW, Fraumeni Jr JF (1991) Rising incidence of adenocarcinoma of the esophagus and gastric cardia. JAMA 265: 1287 1289
Brown LM, Silverman DT, Pottern LM, Schoenberg JB, Greenberg RS, Swanson GM, Liff JM, Schwartz AG, Hayes RB, Blot WJ (1994) Adenocarcinoma of the esophagus and esophagogastric junction in white men in the United States: alcohol, tobacco, and socioeconomic factors. Cancer Causes Control 5: $333-340$

Cancer Research Campaign (1998) Factsheet 1.1 Incidence - UK. London: Cancer Research Campaign 
Cancer Research Campaign (1999) Cancer Statistics Mortality - UK. London: Cancer Research Campaign

Going JJ, Keith WN, Neilson L, Stoeber K, Stuart RC, Williams GH (2002) Aberrant expression of minichromosome maintenance proteins 2, 5 and Ki-67 in dysplastic squamous oesophageal epithelium and Barrett's mucosa. Gut 50: $373-377$

Hu J, Nyren O, Wolk A, Bergstrom R, Yuen J, Adami HO, Guo L, Li H, Huang G, Xu X (1994) Risk factors for oesophageal cancer in northeast China. Int J Cancer 57: 38-46

Iftikhar SY, James PD, Steele RJ, Hardcastle JD, Atkinson M (1992) Length of Barrett's oesophagus: an important factor in the development of dysplasia and adenocarcinoma. Gut 33: $1155-1158$

Kearsey SE, Labib K (1998) MCM proteins: evolution, properties, and role in DNA replication. Biochim Biophys Acta 1398: 113-136

Liu SF, Shen Q, Dawsey SM, Wang GQ, Nieberg RK, Wang ZY, Weiner M, Zhou B, Cao J, Yu Y (1994) Esophageal balloon cytology and subsequent risk of esophageal and gastric-cardia cancer in high-risk Chinese population. Int J Cancer 57: 775-780

Macdonald CE, Wicks AC, Playford RJ (2000) Final results from 10 year cohort of patients undergoing surveillance for Barrett's oesophagus: observational study. BMJ 321: $1252-1255$

McNeil BJ, Hanley JA (1984) Statistical approaches to the analysis of receiver operating characteristic (ROC) curves. Med Decis Making 4: $137-150$

Miros M, Kerlin P, Walker N (1991) Only patients with dysplasia progress to adenocarcinoma in Barrett's oesophagus. Gut 32: $1441-1446$

Newnham A, Quinn MJ, Babb P, Kang JY, Majeed A (2003) Trends in the subsite and morphology of oesophageal and gastric cancer in England and Wales 1971-1998. Aliment Pharmacol Ther 17: 665-676

Office for National Statistics England and Wales (1999) Registrations of cancer diagnoses in 1993-96, England and Wales. Health Stat Q 4: $59-70$

Riddell RH (1996) Early detection of neoplasia of the esophagus and gastroesophageal junction. Am J Gastroenterol 91: 853-863
Rolon PA, Castellsague X, Benz M, Munoz N (1995) Hot and cold mate drinking and esophageal cancer in Paraguay. Cancer Epidemiol Biomarkers Prev 4: 595-605

Sepehr A, Razavi P, Saidi F, Salehian P, Rahmani M, Shamshiri A (2000) Esophageal exfoliative cytology samplers. A comparison of three types. Acta Cytol 44: 797-804

Shu YJ (1983) Cytopathology of the esophagus. An overview of esophageal cytopathology in China. Acta Cytol 27: 7-16

Stoeber K, Halsall I, Freeman A, Swinn R, Doble A, Morris L, Coleman N, Bullock N, Laskey RA, Hales CN, Williams GH (1999) Immunoassay for urothelial cancers that detects DNA replication protein $\mathrm{Mcm} 5$ in urine. Lancet 354: 1524-1525

Stoeber K, Swinn R, Prevost AT, de Clive-Lowe P, Halsall I, Dilworth SM, Marr J, Turner WH, Bullock N, Doble A, Hales CN, Williams GH (2002) Diagnosis of genito-urinary tract cancer by detection of minichromosome maintenance 5 protein in urine sediments. J Natl Cancer Inst 94: 1071 - 1079

Stoeber K, Tlsty TD, Happerfield L, Thomas GA, Romanov S, Bobrow L, Williams ED, Williams GH (2001) DNA replication licensing and human cell proliferation. J Cell Sci 114: 2027 -2041

Urschel JD, Vasan H (2003) A meta-analysis of randomized controlled trials that compared neoadjuvant chemoradiation and surgery to surgery alone for resectable esophageal cancer. Am J Surg 185: 538-543

Wang HH, Sovie S, Zeroogian JM, Spechler SJ, Goyal RK, Antonioli DA (1997) Value of cytology in detecting intestinal metaplasia and associated dysplasia at the gastroesophageal junction. Hum Pathol 28: $465-471$

Williams G, Stoeber K (1999) Clinical applications of a novel mammalian cell-free DNA replication system. Br J Cancer 80: 20 -24

Williams GH, Romanowski P, Morris L, Madine M, Mills AD, Stoeber K, Marr J, Laskey RA, Coleman N (1998) Improved cervical smear assessment using antibodies against proteins that regulate DNA replication. Proc Natl Acad Sci USA 95: 14932-14937

Wright TA, Gray MR, Morris AI, Gilmore IT, Ellis A, Smart HL, Myskow M, Nash J, Donnelly RJ, Kingsnorth AN (1996) Cost effectiveness of detecting Barrett's cancer. Gut 39: 574-579 